\title{
LA ARAUCANA: UN TEXTO QUE GENERA UN CONTEXTO ${ }^{1}$
}

\section{LA ARAUCANA: A TEXT THAT GENERATES A CONTEXT}

\author{
Bernardo Subercaseaux \\ Universidad de Chile \\ besuberc@uchile.cl
}

\begin{abstract}
Los clásicos son esos libros que nos llegan trayendo impresa la huella de las lecturas que han precedido a la nuestra, y tras de sí la huella que han dejado en la cultura o en las culturas que han atravesado... Si leo La Araucana en el texto de Alonso de Ercilla, no puedo olvidar todo lo que la resistencia araucana a la Conquista ha llegado a significar a través de los siglos, y no puedo dejar de preguntarme si esos significados estaban implícitos en el texto o si son incrustaciones o deformaciones o dilataciones. $^{2}$
\end{abstract}

Italo Calvino

\begin{abstract}
Resumen:
El artículo examina la recepción de La Araucana (1568-1590) por patriotas americanos y por figuras de la Independencia de Chile, que leyeron la obra como un documento histórico que enaltecía a los araucanos presentandolos como un pueblo heroico e indomable. A partir de esta recepción se inventa una tradición que vincula las luchas por la Independencia con la que llevaron a cabo los araucanos contra la Corona española. El artículo revisa la recepción de la obra de Ercilla entre la elite criolla, entre líderes militares e intelectuales de la Patria Vieja (1810-1814) y luego de la batalla de Chacabuco (1817-1828), también entre los miembros más prominentes de la generación de 1842. Además la recepción que tuvo entre naturalistas y viajeros. Simbólicamente se advierte en estas lecturas una glorificación idealizada de los araucanos y de sus principales héroes, generándose a partir de ellas un doble discurso, que, por una parte, los glorifica como ancestros libertarios de la nación, y, por otra, los invisibiliza y maltrata en cuanto sujetos reales con una cultura propia y diferente, planteando con una perspectiva asimilacionista que deben ser civilizados y dejar de ser lo que son, doble discurso que de alguna manera persiste hasta el día de hoy.
\end{abstract}

Palabras clave: La Araucana, recepción, glorificación idealizada, doble discurso, texto y contexto.

\footnotetext{
Abstract:

The article examines the reception of Alonso de Ercilla's La Araucana (1568-1590), by spanish american patriots and by figures of the Independence of Chile, who read the work as an historical document that exalted the Araucanians by presenting them as a heroic and

${ }^{1}$ Artículo derivado de FONDECYT Proyecto Regular 1170306 sobre La Araucana.

${ }^{2}$ Italo Calvino. Por qué leer los clásicos.Tusquets (Marginales, 122), 1993. Calvino ejemplifica con la Odisea de Homero, nosotros nos tomamos la licencia de reemplazar la Odisea y Homero por La Araucana y Alonso de Ercilla.
} 
indomitable people. In regard to this readings, a tradition is invented that links the struggle for independence with the one that the Araucanians faught against the Spanish Crown. The article reviews the reception that Ercilla's work had among military and intellectual leaders during the Patria Vieja (1810-1814) and after the Battle of Chacabuco (1817-1828) Also among the most prominent members of the generation of 1842. Also among scientist and travelers.Symbolically this readings show a glorification of the Araucanians and their most oustanding heroes, generating a double discourse that, on the one hand glorifies them as libertarian ancestors of the nation, and, on the other, makes them invisible or mistreats them as real subjects with a different culture, proposing with an assimilationist point of view that they should be civilized and therefore stop being what they are, a double discourse that somehow persists to this day.

Key words: La Araucana, reception, idealized glorification, double discourse, text and context.

Recibido: 23 de noviembre de 2020

Aceptado: 09 de junio de 2021

\section{Los precursores y la Patria Vieja}

A pesar de ser un poema épico renacentista, enmarcado en el Imperio de Felipe II, La Araucana (1568-1590) de Alonso de Ercilla, contribuyó a la invención de una tradición araucanista que fue funcional a la elite criolla de la Capitanía General de Chile, en una perspectiva de Independencia y construcción de la nación. Cabe señalar, de partida, que el gentilicio araucano es una invención de Ercilla y su poema. Una etiqueta que desde el discurso colonial se les (im)puso a quienes habitaban la provincia de Arauco o la región que va desde el sur del río Biobío hasta el río Toltén, habitantes del Wallmapu que ni se reconocían ni se identificaban con el gentilicio ercillano. Con el tiempo, sin embargo, se fueron adecuando a este rótulo, utilizándolo incluso en distintas asociaciones en las primeras décadas del siglo $\mathrm{XX}^{3}$. Durante la Colonia para los españoles el gentilicio araucano equivalía a "indios de guerra" a diferencia de "indios amigos" o "indios de paz". El gentilicio mapuche con el que se identifican hoy día -en contrapunto con el de araucanosolo data del siglo XVIII ${ }^{4}$. Nosotros, al referirnos a los habitantes de la Araucanía en la segunda mitad del siglo XIX, posterior a la mal llamada pacificación, nos inclinamos por el

\footnotetext{
3 Entre otras, Sociedad Caupolicán Defensora de la Araucanía (1910), Moderna Araucanía (1916), Federación Araucana (1921), Unión Araucana y Corporación Araucana en las década del 30. Pedro Cayuqueo, Historia secreta mapuche, Catalonia, Santiago, 2017.

${ }^{4}$ Pedro Cayuqueo, op.cit. Luz María Méndez. Cultura y sociedad en Chile.Nuevas miradas a los siglos XVI, XVII y XVIII. Universitaria, 2019.
} 
gentilicio "araucano-mapuche", que integra el pasado con el presente, el afuera con el adentro.

La tradición araucanista tuvo antecedentes previos a la Independencia en el patriotismo americano de Francisco de Miranda y Simón Bolívar. En Londres, a fines del siglo XVIII, Francisco de Miranda (1750-1816) tuvo estrecho contacto con Bernardo O’Higgins (1778-1842), que como hijo natural se apellidaba entonces Riquelme. Enviado por su padre, O’Higgins estudió en Inglaterra entre los 17 y 20 años. En sus cartas y memorias siempre recuerda a Miranda como un apóstol de la emancipación, como el mentor a quien le debía sus ideales patrióticos. En Londres, la casa de Miranda fue durante años un semillero de ideas libertarias, frecuentada también por otros jóvenes americanos, entre ellos, José de San Martín, Fray Servando Teresa de Mier y Antonio Nariño. El venezolano fue el creador de varias sociedades patrióticas de carácter secreto: la Gran Reunión Americana y la Logia de los Caballeros Racionales, una de ellas fue la Logia Lautaro o Lautarina, que tuvo presencia en Cádiz, Buenos Aires, Santiago, Mendoza y Montevideo. Aunque ostentaban el título de Logias, más que asociaciones estrictamente masónicas fueron sociedades secretas de carácter político patriótico. El matiz clandestino y la fachada masónica contribuían a mantener la mística entre los afiliados y a evitar la vigilancia y persecución por parte del gobierno español ${ }^{5}$. Antes de 1810 la figura de Lautaro fue en Europa, y entre los precursores de la emancipación, una referencia mítica. Hablamos de mito por tratarse de un personaje histórico encumbrado literariamente en la obra de Ercilla, un personaje que se transformó desde fines del siglo XVIII en un símbolo legendario de la lucha por la libertad del continente.

¿Cómo llego Miranda a la figura de Lautaro? Es posible que haya leído $L a$ Araucana o el Compendio del Reino de Chile (1795) de Juan Ignacio Molina, obras que como hemos señalado en otra oportunidad- circularon en varias ediciones en Europa ${ }^{6}$. Lo más probable, sin embargo, es que supo de Lautaro a través de su relación con el joven O’Higgins. En 1798 Bernardo O’Higgins se autopercibe como heredero del espíritu de

\footnotetext{
5 José Antonio Ferrer. "Las logias Lautaro, los Caballeros Racionales y el movimiento independista americano". Biblioteca Jurídica Virtual del Instituto de Investigación Jurídica de la UNAM, www.juridicos.unam.mex

${ }^{6}$ Bernardo Subercaseaux. "La Araucana y el Abate Juan Ignacio Molina", artículo inédito enviado a la Revista Universum de la Universidad de Talca. También "La Araucana: recepción en España y Europa. Nacionalismo literario, canon y migración”. Revista Universum, vol. 35, 2020, pp. 188-219.
} 
Lautaro, así se presenta ante Miranda afirmando que desciende del héroe ${ }^{7}$. En los patriotas americanos de la primera hornada había una clara conciencia de que la resistencia de los araucanos contra el Imperio Español era una excepción en el continente y un antecedente auspicioso para la Independencia. Simón Bolívar así lo consigna en la Carta de Jamaica (1815) al referirse al caso de Chile en que los indómitos araucanos -dice- serán un ejemplo sublime para la liberación e independencia de esa región.

En cuanto al patriotismo nacional éste se hace patente en situaciones y testimonios que involucran a José Miguel Carrera, Camilo Henríquez y La Aurora, a Bernardo O’Higgins, Ramón Freire, Juan Egaña y a Francisco Antonio Pinto. Estando en España, José Miguel Carrera (1785-1821), imbuido también de las ideas de Miranda, se afilió en Cádiz a la Logia Lautaro. Al regresar a Chile, en 1811, desempeñó un rol fundamental en la instalación de la nación en la etapa de la Patria Vieja (1811-1814), liderando el sector más radical frente a quienes desde los sucesos de Bayona en 1808 planteaban mantenerse leales a Fernando VII, preso entonces por las fuerzas napoleónicas. Ocupando varios cargos directivos y en un contexto de disputa entre sectores de la elite criolla (fidelistas versus independentistas, unitarios versus federalistas o regionalistas) fue responsable de instalar un imaginario republicano de la nación (la constitución de 1812, el Senado, la imprenta y periódico La Aurora, la fundación del Instituto Nacional, el primer escudo y primera bandera del país). Carrera vinculaba la Independencia de Chile con la independencia de Arauco. De allí que en el Primer Escudo Nacional, ordenado por él en 1812, estén simbólicamente presentes el pasado araucano y el ideal republicano:

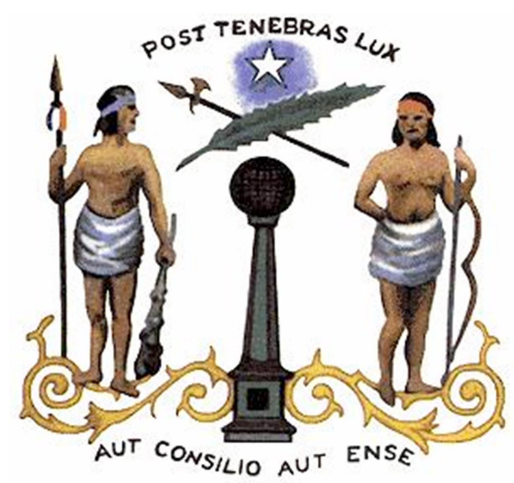

Escudo de la Patria Vieja: (“Después de las tinieblas, la luz” y “O por consejo o por espada”)

\footnotetext{
${ }^{7}$ Francisco Martínez Hoyo. "Francisco Miranda, mentor de O’Higgins”. El mundo de la palabra, las ideas y los ideales. Revista Latinoamericana de Ensayo, 2014.
} 
Debido a que no se conserva el original, la imagen ha sido configurada a partir de descripciones de Manuel Talavera y Fray Melchor Martínez, pero puede considerarse como verídica debido a que Talavera fue testigo presencial de una celebración en la Moneda (el 30 de septiembre de 1812), en que se enarboló y celebró el Escudo con la imagen que antecede. También la crónica de Talavera da cuenta que de las 61 mujeres que asistieron al baile, dos de ellas, aunque eran criollas, estaban vestidas con traje de araucanas, exaltando su patriotismo y ancestros. En este primer escudo están presentes todas las matrices de sentido y los componentes culturales afines al pensamiento ilustrado y republicano, también a la concepción del pasado araucano como antecedente de la nueva nación. La pareja de indígenas están idealizados en la medida que aparecen como tales en su vestimenta, pero inscritos en un marco de símbolos y lemas del neoclasicismo ilustrado europeo. De partida los dictum en latín aunan el mundo clásico con las ideas de la ilustración, contraponiendo la oscuridad a la luz, lo premoderno (la superstición y la ignorancia) al mundo de la razón y de la libertad. Desde la revolución francesa el ideario ilustrado dio lugar a un sistema metafórico lumínico en que enriquecen su sentido literal una larga serie de términos (rayo, relámpago, centella, chispa, apagar, encender, estrella, tinieblas, entre otros) que participan de este campo metafórico, campo que se percibe como universal. En este marco habría que leer la referencia a la luz como símbolo de la razón. Las figuras indígenas, ritualizadas por el emblema en latín, instalan entonces el umbral previo en un imaginario de asimilación, idea cara al indigenismo criollo y a la glorificación idealizada de los araucanos que emerge del texto de Ercilla.

La columna dórica y el globo que sustenta la imagen apuntan por una parte al ideario republicano que alimentó la idea de comunidad a partir de la república griega, una república que no era sólo una fórmula jurídica sino una mentalidad virtuosa que reconocía sus antecedentes en el mundo grecolatino, idea esta fundamental -como ha señalado Mario Góngora- en algunos pensadores de la época como Juan Egaña. Por otra parte, el globo o mundo sostenido por la columna dórica apunta a la universalidad de los emblemas contenidos en el escudo, a la idea de humanidad. Recordemos que uno de los artículos más relevantes redactados por Camilo Henríquez en La Aurora (7 de mayo de 1812) se titula "De la influencia de los escritos luminosos sobre la suerte de la humanidad". En la 
perspectiva de este pensamiento, se es primero ser humano y parte de la humanidad, y luego chileno, argentino, francés, araucano u otro. El primer escudo tiene por ende un aura pannacional, en la medida que integra distintas tradiciones culturales en un cosmopolitismo republicano idealizado ${ }^{8}$.

La naturaleza está representada en los laureles estilizados en que descansan los indígenas y también en la palma que se cruza con la alabarda. Una naturaleza que simboliza el progresismo en que se inscribe el carro de la historia y en el futuro. La estrella de 5 puntas que corona la imagen es un símbolo doble, por una parte es el pentaalpha de la masonería con resabios ilustrados, emblema de la perfección y del supremo saber y por otra el weinalfe mapuche (nombre que asignaban al planeta Venus, imagen que Lautaro usó como pendón de guerra contra los españoles), emblema que está también en la estrella de 5 puntas de la primera bandera chilena. El mundo aborigen y el mundo criollo aparecen por ende -en una lectura semiótica- ensamblados, lo que traduce el intento de incorporar a los araucanos al imaginario de la nación. El conjunto de elementos que conforman el cuadro están traspasados por un optimismo histórico, en que confluyen la naturaleza, las armas, la tradición grecolatina, y el pasado indígena, un mundo nuevo, una tradición que perfila una nación hija de Europa, pero también de un mundo previo. Las lanzas nativas y la alabarda o espada occidentales están unidas y hermanadas, también las ideas. Lo que era heterogéneo y diverso está homogeneizado, simbolizado en un ideal de asimilación en que se desvanece la diferencia, y se ignora el desacomodo entre la utopía y la realidad, entre lo europeo y lo nativo, entre la nación moderna a la que se aspira y un mundo araucano al que la independencia de Chile le fue en los hechos ajena. En la década de 1820, cuando las fuerzas realistas se desplazaron hacia el sur y se instalaron en la Araucanía "encontraron poderosos aliados en (varios) caciques de la zona" (Cavieres 76).

Durante el gobierno de José Miguel Carrera se gestionó la adquisición en Estados Unidos de la primera imprenta traída a Chile, nombrándose como editor de La Aurora a

\footnotetext{
${ }^{8}$ En base a unos sellos utilizados por el Estado en decretos y credenciales de 1814 y 1815 , y también en una versión del Escudo de Blanchard Chesi publicada en la Revista Zig-Zag, septiembre de 1912, el estudioso José Miguel Barros señala la posibilidad de que las dos figuras del escudo no sean indígenas, sino dos dioses romanos (http://www.soberaniachile.cl/historia_mitos_y_errores_sobre_los_simbolos_patrios_chilenos.html) Esta sugerencia no invalida sino que confirma la idea republicana de un pasado aborigen pero que fue también clásico y de dignidad grecolatina. Parece, en todo caso, más plausible considerar como reales las imágenes reproducidas que se basan en los testimonios de Talavera y Fray Melchor Martínez, pues las que muestra José Miguel Barros corresponden sólo a sellos.
} 
Fray Camilo Henríquez (1769-1825). Imbuido de un espíritu ilustrado Henríquez bautizo al rudimentario artefacto como "la máquina de la felicidad". Varios artículos de La Aurora abordan el tema araucano, el propio editor los escribió, usando en algunos el seudónimo de "Patricio Curiñacu". Reiteradamente Camilo Henríquez perfila a los araucanos como amantes de la libertad, sosteniendo con optimismo la causa de la asimilación: "los indios escribió- están en estado de considerarse una nación nueva y por consiguiente fácil y dispuesta a ser ilustrada" (Prospecto, febrero 1812, previo a La Aurora).

Concibiéndolos como guardianes del patrimonio nacional, fray Camilo pronostica que los araucanos serán una de las glorias del país:

de los progresos literarios, que hagan en el Instituto (Nacional) los felices ingenios de estos nuestros compatriotas y hermanos, en quienes se conservan puros los rasgos de nuestro carácter nacional (1812a, p 2).

Pero esta no era solo una opinión personal, personajes como Juan Egaña o Manuel de Salas desde un republicanismo criollo percibían el pasado clasico en el mundo araucano, lo que los inducía a un optimismo en la perspectiva de la educación y la asimilación ${ }^{9}$. En una carta de la Sociedad de Patriotas a La Aurora (23,16 de julio 1812, p 4) los miembros de la Sociedad recuerdan que "en derecho el suelo que habitamos no nos corresponde", en consecuencia dicen es necesario que desde ahora "nos llamemos todos indios... para que nuestros hermanos conozcan el digno aprecio que hacemos de ellos".

Varios historiadores se han referido al proceso de glorificación de los araucanos que se dio en las primeras décadas del siglo XIX ${ }^{10}$. El adjetivo "araucano", llegó a ser -como señala Mario Góngora- un modo poético de decir "chileno" ". Los criollos independentistas se consideraban herederos legítimos de los araucanos, cuyo coraje fue una inspiración en las primeras campañas contra el ejército realista. Simbolizaban el nuevo mito patrio. De allí que muchos de los títulos de diarios y organizaciones de ese período aludan a esta identificación. El periódico que en 1813 sucedió a la Aurora se tituló El Monitor Araucano,

\footnotetext{
${ }^{9}$ Véase Bernardo Subercaseaux y Paula Cuadra. "Camilo Henríquez: teatro, republicanismo y modernidad". Alpha, Revista de Artes, Letras y Filosofia, 43, 2016, pp. 127-141.

${ }^{10}$ Entre otros, Mario Góngora, Simón Collier, Julio Pinto, Holdenis Casanova, Armando Cartes y Viviana Gallardo.

${ }^{11}$ Mario Góngora. Estudios de historia de las ideas y de la historia social. Ediciones Universitarias de Valparaíso, 1980.
} 
el primer diario oficial del Estado Chileno se llamó El Araucano; también hubo otros: El correo de Arauco, Década Araucana, Despertar Araucano, Ilustración Araucana e Insurgente Araucano. Como ya hemos señalado una de las Logias más importantes vinculadas a la Independencia fue la Logia Lautaro, también llamada Logia Lautarina. Varios de los navíos que formaron parte de la primer Escuadra Nacional fueron bautizados con nombres de los héroes ercillanos: Lautaro, Tucapel, Galvarino, Caupolicán.

La Aurora se imprimió entre febrero de 1812 y junio de 1813, la incidencia de la obra de Ercilla en esos años se hace patente en algunas publicaciones y documentos. En Libertad, un periódico de pocas hojas que divulgaba las ideas libertarias, en la edición del 6 de septiembre de 1813, se publicó una suerte de arenga anónima: "Ilustración Araucana: sacado de los arcones de la razón”, de los españoles se dice que son "monstruos sedientos del aurífero metal", y, luego, refiriéndose a los criollos independentistas exclama:

\begin{abstract}
¡Aha patriotas.. que tenéis la dicha de habitar el terreno más feraz de la América, recobrad vuestros derechos, imitando en la unión y en la constancia a vuestros ascendientes los araucanos, cuyas cenizas reposan en la urna de la causa sagrada de la libertad....defendamos -les dice-la causa más justa (de) que nos hizo herederos la naturaleza. Revivan entre nosotros Colo colo, Caupolicán, y el inmortal Lautaro, el Scipión americano. (1)
\end{abstract}

Las figuras que se invocan y su jerarquía corresponden al perfil que traza de ellos el poema de Ercilla.

En 1813 en El Monitor Araucano (n ${ }^{\circ}$ 37, 1 julio) se publicó un documento gubernamental con el título de "Reglamento a favor de los ciudadanos indios". El punto de enunciación obedece a "los ardientes conatos" con que el gobierno (de Carrera) "proclama la fraternidad, igualdad y prosperidad de los indios" (130). Establece que quienes residen "en pueblos de indios" tendrán de ahora en adelante los mismos "derechos sociales y de ciudadanía que corresponde(n) a los chilenos" (130). Plantea que serán sacados de sus rucas y se les construirán en la proximidad villas, se les entregará una yunta de bueyes con arado e instrumentos de labranza y semillas. El Gobierno, dice el Reglamento, desea destruir por todos los medios las "diferencias de casta en un pueblo de hermanos". Traduce por lo tanto una voluntad de asimilarlos incorporándolos a una nación cívica, señala como caminos la educación pública y la moral industrial. Plantea además que la "clase ruda y miserable de 
los indios ha sufrido transgresiones de deslindes a sus tierras por los "fuertes hacendados que los rodean" (132). El origen del documento es la constatación de "la extrema miseria, inercia, incivilidad, falta de moral y educación en que viven" en la zona de Arauco. ¿Quiénes suscriben el Reglamento de 1813? Nada menos que Camilo Henríquez, Juan Egaña y Mariano Egaña.

Se hace patente entonces una paradoja: la misma voz que glorifica e idealiza a los araucanos advierte en ellos una condición paupérrima y miserable que requiere civilizarlos. Contraste que se hace presente también en relatos como el de J. E. Coffin, joven norteamericano que viajo en un navío que traía armas para los patriotas, pero que fue confiscado por los realistas en 1817, y llevado a Talcahuano. Una vez liberado Coffin recorrió la cordillera de Nahuelbuta y relató su experiencia en Diario de un Joven Norteamericano, publicado en Boston en $1823^{12}$. Señala que aunque las tribus de la zona son independientes se hallan a menudo en guerra unas con otras. "Trescientos años atrás dice- probablemente constituían una de esas formidables naciones que opusieron tan tenaz resistencia a la conquista española" y, luego agrega, hoy "sería inútil descubrir en ellos las huellas de ese valor firme y sistemático que la historia reconoce en sus antepasados... mucho menos puede distinguirse en ellos...ese entusiasmo, magnanimidad y heroísmo, cuyas muestras ha descrito Ercilla con tanta belleza y energía" (200-201).

Son documentos que ponen de manifiesto un contexto en que opera un doble discurso que tiene su origen en la época de la Independencia, e incluso antes, con precursores como el Abate Molina. Por una parte glorificación idealizada de los araucanos y por otra, una realidad expoliada y miserable, una ciudadanía política simbólica que nunca fue real. Un doble discurso que se proyecta hasta el día de hoy en estatuas, calles y pueblos que honran a los araucano-mapuches a lo largo del país, y por otra parte un tratamiento que no se condice con esos homenajes, y que trasunta una perspectiva asimilacionista tal vez bien intencionada pero ineficaz, ineficaz debido a que no responde a las demandas araucano-mapuche de independencia y libertad, que son precisamente los valores que se les ensalzan simbólicamente. Doble discurso que tiene algunos momentos en que la paradoja se revela extrema, como por ejemplo durante la ocupación de la Araucanía, en la mal llamada "Pacificación" en la segunda mitad del siglo XIX. En efecto, en la batalla final de

\footnotetext{
${ }^{12}$ J. E. Coffin. Diario de un joven norteamericano. Editorial Francisco de Aguirre, 1968.
} 
1883, que culminó décadas de despojo con connotaciones de empobrecimiento y exterminio $^{13}$, uno de los batallones gubernamentales que participó en la contienda fue el batallón Caupolicán, que había actuado en la Guerra del Pacífico. O sea el araucano simbólico y mítico -que servía como etiqueta y homenaje de ese batallón- enfrentando y matando al araucano-mapuche real. Doble discurso que es aludido con frecuencia en la poesía mapuche contemporánea, como se advierte en un verso de David Aniñir (1971-) "Somos los nietos de Lautaro tomando la micro/ para servirle a los ricos"

¿Cabe acaso culpar a la obra de Ercilla de esta paradoja, o de dar origen a una falsificación histórica? (como ha sugerido equivocadamente el historiador Sergio Villalobos ${ }^{15}$ ) Pensamos que no, una cosa es una obra literaria y otra son las lecturas que se hacen de ella. Una cosa es el poema épico de Ercilla y otra la recepción y apropiación de su contenido. De hecho el lector implícito y apelado por el poema es el lector culto español y europeo, es también el monarca, son los letrados europeos que sintonizan con el humanismo, pero en ningún caso el lector hispanoamericano y menos chileno. Las intenciones de un autor - como nos indica la teoría de la recepción- nunca agotan el significado de una obra, pues como ocurre en este caso, a medida que la obra pasa de contexto en contexto, se extraen de ella nuevos significados no previstos ni por el autor ni por el público de su época. De modo que cuando se afirma que el indigenismo criollo en tiempos de la Independencia fue "intensamente influido por el mito épico de los guerreros de La Araucana" (Cartes 20) ${ }^{16}$, resulta más exacto afirmar que fue influido por lecturas que desde cierto horizonte de expectativas se hicieron de la obra. Lecturas que en el caso que nos ocupa se instalan en un determinada situación histórica, en siglos de resistencia y en un país nuevo que en 1810 tenía alrededor de 800 mil habitantes de los cuales no más de un $10 \%$ sabía leer, una comunidad criolla de elite imbuida del pensamiento ilustrado en su vertiente republicana, una sensibilidad eurocéntrica de corte neoclásico, y un trasfondo de incipiente nacionalismo de cuño patriótico liberal. Ese fue el sustrato que auspició la glorificación idealizada de los araucanos, a la que por cierto la obra de Ercilla -por su virtualidad semántica- no opuso resistencia.

\footnotetext{
${ }^{13}$ Véase al respecto José Bengoa. Historia del pueblo mapuche (siglos XIX y XX). Lom Editores, 2000.

${ }^{14}$ Davir Aniñir del poema "Mapurbe". Mapurbe. Venganza a raiz. Editorial Pehuen, 2007.

${ }^{15}$ Sergio Villalobos. La Araucanía. Mitos y falsedades. Universidad Bernardo O’Higgins, 2015.

${ }_{16}$ Armando Cartes. "Arauco, matriz retórica de Chile: símbolos, etnia y nación". Si Somos Americanos. Revista de Estudios Transfronterizos, XIII, 2, 2013.
} 
Desde la Independencia emana este doble discurso y esta lectura de La Araucana como fuente de identidad patria, la que se proyecta de alguna manera -como hemos señalado- hasta el día de hoy. Es en este horizonte de expectativas que se da la onomástica ercillana y el nombramiento de periódicos, buques, logias, calles y estatuas, hasta bautizar con el nombre de uno de sus personajes -Colocolo- al club de futbol más popular del país ${ }^{17}$. Puede afirmarse, entonces, que la relación que se establece entre la Independencia y La Araucana tiene un carácter fundacional, en la medida que genera un contexto, que desde un texto contribuye a darle raigambre libertaria a la idea de una nación con ancestro, lo que da pie para una alabanza simbólica del pasado araucano, la que sin embargo tiene su contrapunto en una realidad que los excluye e invisibiliza como sujetos reales con una cultura diferente.

\section{Después de Chacabuco}

Entre los patriotas que desempeñaron un rol político, militar e intelectual después de 1817 y que dejaron testimonio de su vínculo con la obra de Ercilla y con Arauco, cabe mencionar a Bernardo O’Higgins, Juan Egaña, Ramón Freire y Francisco Antonio Pinto. O'Higgins fue sin duda la figura que tuvo un mayor conocimiento y familiaridad con el mundo araucano. Estudio en el Colegio de los Naturales de Chillán, construido por los jesuitas y regido por los franciscanos desde 1786, allí estuvo interno conviviendo con hijos de los caciques de la zona de Chillán, Los Ángeles y Concepción. Allí aprendió mapudungun. En una carta de 1837 a su secretario dice "mis primeros camaradas de juego fueron los araucanos y la historia que primero conocí (a través de La Araucana) fue la de (los) héroes y sabios de ese pueblo inconquistable" ${ }^{\prime 1}$. Hay antecedentes vagos de que estando en Las Canteras (la hacienda que heredó) O'Higgins fue padre de una hija natural con una sirvienta mapuche, lo que si está documentado es que a Petronila Riquelme -que así se llamaba la posible hija- partió con él al Perú cuando abdicó y salió al exilio (1823) instalándose en Lima, donde ella se casó. Hasta hoy día viven peruanos que en ese país dicen ser descendientes de O’Higgins.

\footnotetext{
${ }^{17}$ El rótulo se ha lexicalizado y nos nos llama la atención, pero piensese lo extraño que sería si el Real Madrid se llamará Don Quijote, o Lazarillo de Tormes, o El Buscón.

${ }^{18}$ Citada por Julio Pinto y Verónica Valdivia. ¿Chilenos todos? La construcción social de la nación 18101840), Lom, Santiago, 2017, p. 58.
} 
María Graham, la viajera inglesa que llegó a Chile en 1822, en su Diario describe una visita al Director Bernardo O’Higgins y relata que cuando conversaba con él aparecieron varias niñitas de "aspecto salvaje", las que corrían "hacia él colgándose de sus rodillas", luego supo que eran huérfanas araucanas que habían sido rescatadas de una matanza en el campo de batalla. "Una de ellas", hija de un cacique, la impresionó particularmente debido a que Rosa, la hermana del Director Supremo, la trataba como una madre a su hija (Akel 133-134) ${ }^{19}$. También dice que escuchó a O'Higgins hablar con estas muchachas en mapudungun. Esta proximidad familiar del libertador con los araucanos llevó a que un curioso y estrafalario personaje, el profesor de arte César Navarrete que ejercía en el liceo Abate Molina de Talca, publicara - con el amparo del gobierno y con el seudónimo de Lonko Kilapan- el libro O’Higgins es araucano (Universitaria, 1978). Bajo el amparo de Pinochet y como quinta columnista de organizaciones mapuches, Navarrete se proclamó historiador de la raza, presidente de la Confederación Indígena de Chile, Secretario de la Academia de la Lengua Araucana y Presidente del Instituto Araucano de Parapsicología, todas organizaciones creadas o más bien inventadas por él, que a pesar de ser inexistentes contaban con el amparo del régimen. En la publicación, editada por la Editorial Universitaria, el Lonko Kilapan afirma que O’Higgins habría nacido de mujer araucana y de Ambrosio O'Higgins, se basa, entre otros argumentos, en que el Director Supremo tenía una mancha coaxial en la espalda, propia de los araucanos. Señala que O’Higgins llevaba siempre consigo dos libros: La Araucana y el Compendio del Reino de Chile del abate Juan Ignacio Molina. También asevera -sin citar documentos- que O'Higgins en Londres, cuando era estudiante, habría dictado conferencias sobre La Araucana. El trasfondo de este episodio y la posibilidad de que se editara el libro residen por una parte en el amparo que recibió de la dictadura, pero también en que efectivamente los patriotas de la Independencia intentaron forjar una nación que se consideraba como hija y hermana de los araucanos.

Pero más allá de esta relación personal, hay varios testimonios y documentos que muestran la vinculación de O'Higgins como gobernante con la obra de Ercilla y sus esfuerzos por integrar a los indígenas al bando republicano. Como jefe militar, ya en 1814, arengaba a sus soldados a pelear como lo habían hecho Lautaro, Galvarino y Caupolicán, lo

\footnotetext{
${ }^{19}$ Regina Akel. María Graham. Una biografia literaria. Editorial Universitaria, 2012.
} 
que lleva a suponer que los héroes ercillanos eran de dominio público. El 13 de marzo de 1819, siendo Director Supremo envió una carta “A nuestros hermanos los habitantes de la frontera del Sud" en que los invitaba a reunirse al bando republicano señalando la voluntad de una alianza "indisoluble", reconociendo su independencia y dejando ver que se trataba de dos estados. "Os habla el Jefe de un pueblo libre y soberano, que reconoce vuestra independencia" ${ }^{20}$. Antes, el 4 de marzo, en un Decreto dictamina que deben ser considerados ciudadanos chilenos con los mismos derechos que todos los nacidos en el país. Se trata de una ciudadanía que los incluía en la nación cívica pero no en una ciudadanía política, puesto que para votar era necesario saber leer y escribir y tener propiedades a su nombre. Como señala Gabriel Cid lo que hizo O’Higgins fue "subsumir la heterogeneidad cultural de la República dentro de una categoría inclusiva: la ciudadanía". Se trata de una ciudadanía abstracta de vocación igualitaria, y, paralelamente de una propuesta de reconocimiento a la provincia de Arauco que sintonizaba con las ideas federales $^{21}$. Un intento político de atraer a los araucanos a la causa republicana, en la que subyace también su conocimiento y vínculo personal con ese mundo. De hecho cuando O’Higgins abdicó y se fue al exilio un cacique le ofreció acogerlo en el Estado Araucano: “cuando no tengas otro asilo -le escribió- cuenta con tus araucanos" (Pavez 170) ${ }^{22}$.

Juan Egaña (1769-1836), quien colaboró con Camilo Henríquez en La Aurora, publicó en un periódico en formato de folletín Cartas Pehuenches, o Correspondencia de dos indios naturales del Pire-Mapu, o sea la cuarta Tetrarquía de los Andes, el uno residente en Santiago y el otro en las cordilleras Pehuenches (1819). Son 12 cartas en que el pehuenche que vive en Santiago crítica algunos aspectos del ser chileno, en una especie de etnografía al revés, con un punto de vista afín al indigenismo criollo de tinte republicano. Egaña recurre al imaginario ercillesco cuando compara la sabiduría de Melillanca con la de Colo Colo. En la Primera Carta Melillanca dice "La actual revolución de Chile tiene el objeto más justo y necesario que puede interesar a un pueblo: es el mismo

\footnotetext{
${ }^{20}$ Andrés Bello en Manual de Derecho de Gentes (1832) siguiendo a Jeremias Bentham define a Nación o Estado como "una sociedad de hombres que tiene por objeto la conservación y felicidad de los asociados; que se gobierna por leyes positivas emanadas de ella misma y es dueña de una porción de territorio".

${ }^{21}$ Gabriel Cid. Historia intelectual de la Independencia de Chile. UDP, 2019

22 Jorge Pavés. Cartas Mapuche, Siglo XIX. Ocho Libros/Colibrís, Fondo de Publicaciones Americanistas, 2008.
} 
por el cual nuestra nación estuvo más de doscientos años en guerra"23 (34). Juan Egaña es uno de los más destacados representantes del republicanismo, corriente de pensamiento que en el ámbito de la ilustración se diferencia del liberalismo, mientras este último se centra en los derechos individuales, en la libertad de conciencia y de imprenta, el republicanismo se enfoca más bien en los derechos colectivos, son dos tendencias emparentadas que coexisten en el siglo XIX. La generación de la Independencia estuvo más próxima al republicanismo mientras la generación de 1842 lo estuvo del liberalismo.

Ramón Freire (1787-1851), quien sucedió como Director Supremo a O'Higgins, fue partidario -en sintonía con el federalismo- de una descentralización que contemplara los referentes regionales. Aunque batalló con los araucanos (masacre de Lefquenches en Arauco), hizo esfuerzos - como su predecesor- por aproximar el mundo araucano a la república. Durante el gobierno de Freire se reinstaló la noción de los mapuches como hermanos y aliados. En 1825 se realizó el Parlamento y Tratado de Tapihue (1825) el que ratifica la ciudadanía de los araucanos con todas sus prerrogativas, se les reconoce también una territorialidad diferenciada. Fue el primer tratado de paz entre la República y varios caciques. Ramón Freire decía que los mapuches eran "nuestros padres", los chilenos afirmaba "somos hijos de Caupolicán, Colo-colo y Lautaro" (Cartes 197) ${ }^{24}$.

Francisco Antonio Pinto (1785-1858), que fue parte del gobierno de Freire y que lo sucedió como presidente, declara en sus Memorias la impresión que siendo joven le causo la lectura de Ercilla:

Por primera vez leí en ese tiempo La Araucana... nos reuníamos en corrillo para saborear su lectura. No era porque gustáramos de la belleza de su poesía que no estábamos en estado de saber apreciar, sino las heroicas hazañas de los araucanos y españoles que las considerábamos como propias, por ser compatriotas de los primeros y descendientes de los segundos. Esta obra fue la que comenzó a despertar en nuestros corazones amor patrio, sentimientos guerreros, sed de gloria $\mathrm{y}$, un vago conato por la Independencia. No era posible considerar las grandes acciones de Caupolicán, Colo colo, Lautaro y otros colosos de nuestra historia sin sentir arder el corazón en deseos de imitarles, y de tener una patria a quien consagrar nuestros servicios ${ }^{25}$ (cit. en Casanova 25)

\footnotetext{
${ }^{23}$ Claudia Zapata. "Cartas Pehuenches”. Historia Crítica de la literatura chilena, Tomo II, Lom, 2018.

${ }^{24}$ Armando Cartes Monroy, op.cit.

${ }^{25}$ Holdenis Casanova. "Entre la ideología y la realidad. La inclusión de los mapuche en la nación chilena (1810-1830)". Revista de historia indígena, 4, 2000.
} 
Se trata de un recuerdo que lo dice todo, explicita una lectura de La Araucana como documento histórico y no como poema, un texto que adorna y mitifica la historia ("heroicas hazañas"), que sirve de base para la invención de una tradición, una tradición que alimentó al patriotismo bélico entre los criollos independentistas. La fecha de la lectura de Pinto corresponde a un momento en que la separación de España no estaba todavía consolidada. Desde sus albores el poema de Ercilla marcó a la elite criolla y aristocrática, generando un discurso que glorificaba a los araucanos reconociendo en su lucha una tradición, se buscaba entonces integrarlos a la futura nación, reconociendo su diferencia pero en un trasfondo de asimilación que implícitamente los menoscababa. Discurso de glorificación idealizada de los héroes ercillanos y de Arauco, que distaba de las condiciones reales de existencia de sus habitantes. Es teniendo en cuenta esta contradicción que dos científicos sociales, el arqueólogo Tom D. Dillehay y el historiador José Manuel Zavala, considerando a La Araucana como un documento histórico, señalan como "especialmente problemáticas... las inexactitudes y divergencias espacio temporales que desde el texto fundador de Ercilla han acompañado las descripciones de los araucanos o mapuches" ${ }^{26}$.

Luego de la batalla de Lircay (1830), derrotados el gobierno pipiolo de Pinto y su sucesor Freire, se da inicio a la etapa portaliana, en que el presidente Joaquín Prieto (17861854) considera a los araucanos enemigos irreconciliables de la civilización, inclinándose por expandir la frontera al sur del Bío bio. En 1835 Javier Bustamante, Ministro del Departamento de Guerra y Marina, señalaba que es "preciso reducir a los bárbaros a un estado de absoluta nulidad, de modo que no puedan ofender". Son años en que prima la dicotomía civilización y barbarie, y un clima muy distinto al que hemos examinado en el período que va desde la Patria Vieja hasta el triunfo conservador en la batalla de Lircay.

\section{La década de 1840}

A comienzos de la década de 1840 se despliega en Santiago un movimiento intelectual de filiación ilustrada y liberal desconocido hasta entonces, un movimiento de

\footnotetext{
26 José Manuel Zavala y Tom D. Dillehay. "El estado de Arauco: frente a la Conquista Española: estructuración sociopolítica y ritual de los araucano-mapuches en los valles Nahuelbutanos durante los siglos XVI y XVII". Chungará, 42, 2010.
} 
letrados que se autopercibe como una posta respecto a la generación de la Independencia, y que consideraba a la etapa portaliana como un interregno autoritario que reinstaló el espíritu retrogrado de la Colonia. La emancipación política requiere -pensaban- una regeneración de la conciencia nacional para complementar la independencia. Agrupados algunos en la Sociedad Literaria de 1842, todos han estudiado en el Instituto Nacional o en el Colegio de Santiago, han sido discípulos de Andrés Bello (1781-1865) y un par de ellos de José Joaquín de Mora. Si bien siguen siendo miembros de una elite criolla de sesgo aristocratizante, hay excepciones, como la del propio Lastarria (1817-1888).

La juventud distinguida- escribe Lastarria- que poco antes estaba reducida al estrecho círculo... de la oligarquía dominante, había recibido dice- un refuerzo...con la nueva generación que se había educado en otros principios y distintas aspiraciones y que sentía estimulada su actividad con el roce de la ilustrada y bulliciosa emigración argentina ${ }^{27}$.

Interactúan con los emigrados de la época de Rosas, entre otros con Domingo Faustino Sarmiento (1811-1888) y Juan Bautista Alberdi (1810-1884). Los intelectuales que en esa década abordaron La Araucana o el tema indígena son además de Andrés Bello, que fue el maestro e interlocutor de todos ellos, el propio Lastarra, Francisco Bilbao (18231865) y algo más joven y más tarde, Benjamín Vicuña Mackenna (1831-1886).

Andrés Bello publicó en 1841 en el diario oficial de gobierno (que dirigía) un juicio crítico sobre el poema ${ }^{28}$, amparado en las ideas de Giambatista Vico, según Vico a cada época social corresponde un tipo de fantasía y un género poético específico. Bello, por primera vez en Chile, realiza una lectura literaria de la obra, leyéndola como una epopeya renacentista que tiene como modelo al Orlando el Furioso de Ariosto. Valora los recursos de su composición, su estilo "llano, templado y natural", y destaca la particularidad de que el poeta sea a su vez actor y narrador de la obra. Considera a La Araucana como "nuestra Eneida", como un poema que inmortalizó la fundación de Chile, lo que es -dijo- un privilegio excepcional entre las naciones modernas. La percibe como piedra angular de la literatura chilena pero también de la nación. Mantuvo, sin embargo, en este plano, cierta

\footnotetext{
${ }^{27}$ José Victorino Lastarria. Recuerdos literarios. Editorial Zigzag, 1967.

${ }^{28}$ Andrés Bello. "La Araucana por don Alonso de Ercila y Zuñiga". El Araucano, 1841 y reproducido en Anales Universidad de Chile, 1, Tomo XXI, 1862, pp. 2-11. Conserva el mismo título y el súbtítulo "Juicio crítico de esta obra por el Señor Rector de la Universidad don Andrés Bello".
} 
ambigüedad entre lo literario y lo histórico. En el juicio crítico de Bello es la grandeza épica de la obra -su calidad estética- la que funciona como testimonio de la grandeza de un pueblo, y no al revés, omite por lo tanto referirse al mundo nativo, a sus héroes y a la lucha legendaria que constituye el asunto del poema. ${ }^{29}$

Lastarria, discípulo irreverente de Bello, inspirado en una lectura histórica de $L a$ Araucana señala en su Guía del Forastero (1841) que los indígenas habían sido los portadores de la libertad frente al despotismo español. En 1844 destaca la situación única que representan los araucanos en la Conquista:

desde sus primeras incursiones en este país, (los españoles) recibieron un desengaño terrible que irrito y mortifico su orgullo en alto grado: encontraron aquí hombres de bronce, en cuyos pechos rebotaban las balas de sus cañones...En Chile no existía el indígena envilecido y pusilánime a quien bastaba engañar para vencer, mandar para esclavizar, sino un pueblo altanero y valiente, que lejos de correr a ocultarse en los bosques, esperaba a su enemigo en campo abierto, porque se sonreía con la seguridad de vencerle y de hacerlo sentir todo el peso de su valor (Lastarria 22-23) 30

Para Lastarria y la generación de 1842 la Colonia constituía una etapa contraria a los fines de progreso, representaba una mentalidad anquilosada que persistió después de la Independencia. Lo único rescatable de los tres siglos coloniales -según Lastarria- fue la lucha de los araucanos por defender su independencia y soberanía, "en esos hechos heroicos -dice- divisamos el fundamento de nuestra libertad política" (Lastarria 15). Lastarria, como la mayoría de los miembros de su generación estudió en el Instituto Nacional, en el cual uno de los textos básicos fue Lecciones sobre la retórica y las Bellas Letras (1798-1801) ${ }^{31}$. José Luis Munarriz, traductor de la versión inglesa del manual (cuyo autor fue el clérigo escocés Hugo Blair), le agregó de su pluma un "Apéndice sobre la poesía épica española" en que refiriéndose a La Araucana, critica la alabanza excesiva que hace Ercilla de los araucanos en desmedro de los españoles, llega a decir que Ercilla

\footnotetext{
${ }^{29}$ Andrés Bello. "La Araucana por don Alonso de Ercila y Zuñiga". El Araucano, 1841 op. cit.

${ }^{30}$ José Victorino Lastarria. Investigaciones sobre la influencia social de la conquista y del sistema coonial de los españoles en Chile. Santiago, Imprenta del Siglo, 1844, pp. 22-23.

${ }^{31}$ Traducción de José Luis Munarriz de Lectures on rethoric and Belles Lettres (1783) del clérigo escocés Hugo Blair, cuya obra recomienda encarecidamente Camilo Hemríquez en La Aurora.
} 
deshonró a su nación. Juicio de Munarriz que debe haber incitado la curiosidad lectora de los estudiantes, para quienes en 1842 desespañolizarse equivalía a chilenizarse.

En sus Memorias, Francisco Bilbao recuerda lo que significó para él la lectura del poema de Ercilla en su infancia, habla de "la luz primitiva que fecundó (en él) La Araucana... la que más tarde" (Bilbao 21) -dice- "recibió la confirmación o la revelación científica del republicanismo eterno que recibí en mi patria independiente" (Bilbao 31$)^{32}$. Expulsado de Chile, Bilbao siguió estudios en Francia con Edgar Quinet y con Jules Michelet y escuchó en una de sus lecciones (1845) decir a Quinet: "Solo Chile parece guardar aún el alma de los antiguos araucanos del poema de Ercilla" (cit. en García San Martín 21). En cartas de Quinet a Bilbao este se despide del joven discípulo con una frase significativa: "Valor querido araucano, combatid, luchad en libertad" (García San Martín $31)^{33}$. En algunas cartas el propio Bilbao se firma como "Pancho el Araucano". En el Evangelio americano cita la obra de Ercilla junto a Bartolomé de las Casas, el Inca Garcilaso de la Vega y Antonio Ulloa, autores cuya visión se distancia del estereotipo colonial sobre los indígenas. En su ensayo "Los Araucanos" (1847) Bilbao valora y cita a La Araucana como una fuente geográfica e histórica fidedigna. Vincula el aspecto de los habitantes de Arauco con una naturaleza indómita y una geografía exuberante. Pero también señala que en cuanto a costumbres, lenguaje y vivienda, los araucanos están en un estado intermedio entre la barbarie y la civilización, juicio en que lo civilizado se rige por el parametro europeo. Se refiere a la transculturación entre el mundo araucano y el español. Por una parte resalta entonces al araucano legendario y a su tradición libertaria, pero, por otra, al referirse al araucano real se ubica como todos los integrantes de la generación de 1842 en una perspectiva de asimilación amparada por la dicotomía barbarie y civilización.

$\mathrm{Su}$ admiración por la obra de Ercilla se mantiene, empero, incólume. En 1862 pocos años antes de su muerte, le escribe desde Buenos Aires a los hermanos Miguel Luis y Gregorio Víctor Amunátegui, proponiéndoles realizar una edición crítica de La Araucana, les pregunta si se enseña el idioma mapuche en el Instituto Nacional:

\footnotetext{
${ }^{32}$ Francisco Bilbao. Lammenais como representante del dualismo de la civilización moderna, París, 1856.

${ }^{33}$ Citas tomadas de Álvaro García San Martín. "Bilbao y Lammenais. Una lección de geopolítica". La Cañada, 2, 2011, pp. 21 y 31 .
} 
Díganme amigos: ¿No se tentaría(n) ustedes a hacer una edición de $L a$ Araucana ilustrada y con notas? Para Chile es la Ilíada...con la idea justísima que ustedes exponen en su libro, como fundador Ercilla de un ciclo literario... sería el libro que el gobierno debiera imprimir en cien mil ejemplares. (Cit. en Sanhueza 235)

Hay diferencias entre el primer Lastarria y Bilbao con Sarmiento, Alberdi y Vicuña Mackenna, aunque todos coinciden en la educación, el progreso y la civilización del indio o como plantea Bilbao, en un proceso de transculturación o hibridez. Los primeros tienden a resaltar el araucanismo desde una lectura histórica de la obra como símbolo de libertad y emancipación; Sarmiento, Alberdi y Vicuña Mackenna, en cambio, se sitúan de preferencia en la dualidad barbarie y civilización, dibujando desde ese paradigma un cuadro negativo de los habitantes de Arauco. Sarmiento explicita su rechazó a la utilización de La Araucana como mito nacional, pues ello frenaba el proceso civilizador, se queja incluso de que una mala poesía (haya) bastado para menospreciar la empresa de la Conquista:

quisiéramos apartar de toda cuestión social a los salvajes, por quienes sentimos sin poderlo remediar, una invencible repugnancia y para nosotros Colo colo, Lautaro y Caupolicán, no obstante los ropajes nobles y civilizados de que los revistiera Ercilla, no son más que unos indios asquerosos, a quienes habríamos hecho colgar ahora, si reapareciesen en una guerra de los araucanos contra Chile, que nada tiene que ver con esa canalla $^{35}$

En una postura similar, aunque más cauta, Juan Bautista Alberdi, viviendo en Valparaíso, en sus Bases afirma no conocer a nadie "de nuestra sociedad que lleve apellido pehuenche o araucano", y luego se pregunta “¿Quién casaría a su hermana o hija con un infanzón de la Araucanía, y no mil veces con un zapatero inglés?”36

Benjamín Vicuña Mackenna, a pesar de haber participado con apenas 19 años en la Sociedad de la Igualdad (1850-1851), fue a la postre uno de los artífices y cruzados más persistentes de la civilización, un constructor de la nación -como lo fue también Bello- en

\footnotetext{
${ }^{34}$ Carta del 16 de enero de 1862, citada por Marcelo Sanhueza. La América no quiere ser imperializada, Tesis doctoral, Universidad de Chile, 2020.

${ }_{35}$ Domingo Faustino Sarmiento. El progreso, Santiago, 28 septiembre de 1844, citado por Francisco Albizú Labbe. "La polémica Andrés Bello/Sarmiento. Su influencia en la formación de la identidad nacional chilena". América: Cahiers de Crical, 21, 1998.

${ }^{36}$ Juan Bautista Alberdi. Bases y puntos de partida para la organización politica de la República Argentina. Valparaíso, Imprenta El Mercurio, 1852.
} 
términos de una modernidad eurocéntrica, la que probablemente, en términos operativos, era para la elite letrada la única deseable y posible. En décadas posteriores, en algunos de sus escritos Vicuña Mackenna ironizó sobre el mesianismo igualitario de Bilbao o sobre el idealismo de los "girondinos" chilenos de 1850. En la década de 1860 fue uno de los propulsores de la ocupación de la Araucanía y, más tarde, de la inmigración de colonos europeos a la zona. Fue crítico de la glorificación idealizada de los araucanos que se basaba en Ercilla, en algunos discursos de 1868 se empeñó en desmitificar la imagen de los araucanos-mapuche como un pueblo guerrero e indómito, refiriéndose a "la nulidad militar de los bárbaros”. A propósito de los debates en el parlamento ante la pregunta de un periodista por la situación de Arauco, respondió lo que sigue:

Para mí, señor (la cuestión de Arauco) no es sino un gran fantasma, fantasma sangriento, que se pasea durante tres siglos en nuestra historia, engañando a todas las generaciones como una ilusión óptica... la ponderada pujanza de los araucanos no era tan temible como nos lo cuenta un poeta ilustre, que por ensalzar las hazañas de los suyos nos ha presentado una raza imaginaria de héroes mitológicos ${ }^{37}$.

Siendo parlamentario liberal, en 1868, Vicuña Mackenna plantea algunos puntos fundamentales que deben tenerse en cuenta sobre la "Pacificación de la Araucanía", entre ellos:

Qué el indio -no el de Ercilla sino el que ha venido a degollar a nuestros labradores del Malleco y a mutilar con horrible infamia a nuestros nobles soldados- no es sino un bruto indomable, enemigo de la civilización porque solo adora los vicios en que vive sumergido, la ociosidad, la embriaguez, la mentira, la traición y todo ese conjunto de abominable grupo que constituye la vida salvaje...El indio ha hecho esclava a la mujer. Ella trabaja, ella siembra, ella encilla aún el caballo en que el indio, convertido en salteador, sale a sus malones. Basta ya de novelas y de poemas... ${ }^{38}$

Vicuña Mackenna señala que los indios "para quien tanto se invoca el derecho, no son sino bandidos y salteadores de camino". Recuerda que "fueron los más implacables

\footnotetext{
${ }^{37}$ Benjamín Vicuña Mackenna. "Primer discurso sobre la Pacificación de Arauco", pronunciado en agosto de 1868, también Discursos parlamentarios, vol. XII de Obras Completas, Universidad de Chile, 1939.

${ }^{38}$ Benjamín Vicuña Mackenna. Discursos parlamentarios, op cit., pp. 391-411.
} 
enemigos de nuestra Independencia”. Lastarria, que también era parlamentario en 1868, aunque no se oponía a la "pacificación", planteaba que el modo de realizarla debía ser diferente, lo decía incluso en términos del gasto que implicaba la ocupación militar de la zona, señala además situaciones de pillaje y bandidaje en contra de los indígenas, propone, aunque no de manera explícita, "dejarlos tranquilos" para evitar el derroche innecesario de recursos y la pérdida de vidas en combates de incierto resultado ${ }^{39}$.

\section{Naturalistas, viajeros y literatos}

A mediados del siglo XIX algunos naturalistas europeos contratados por el Estado desempeñan un rol importante en el mapeo geográfico, mineral, y de la flora y fauna del país, contribuyendo así a la construcción e imagen de la nación. Los más destacados son Claudio Gay (1800-1873) e Ignacio Domeyko (1802-1881). Claudio Gay llegó a Chile en 1828 y dos años después fue contratado por el gobierno de Portales por mediación de Mariano Egaña, fue el primer contrato de varios cuyo propósito era la investigación y descripción del territorio chileno en todos sus aspectos, tarea que tuvo como resultado una Historia Física y Política de Chile de 30 volúmenes, concluida poco antes de su muerte. Entre sus escritos permaneció inédito un texto titulado Usos y costumbres de los araucanos, producto de exploraciones y trabajos de campo realizados por Gay en la década de 1840. El manuscrito fue traducido y editado recientemente por el antropólogo Diego Milos $^{40}$. Se trata en términos de hoy de un estudio y registro etnográfico, que tiene en varios aspectos al texto de Ercilla como fuente, al que Claudio Gay leyó como un documento histórico fidedigno. Lo sigue en la descripción de los rasgos físicos de los héroes araucanos, ratifica las virtudes guerreras y el afán libertario perfilado por Ercilla, constata un espíritu independiente que según el naturalista persiste y sigue siendo motivo de orgullo en los habitantes de la Araucanía. Cita episodios tomados de La Araucana como la arenga de Galvarino y su fuerza moral (Gay 33). Destaca la preparación de los hijos como guerreros desde temprana edad. Respecto a la defensa de su territorio Gay escribe que se "mostraban más comprometidos, más disciplinados y más perseverantes...y lo

\footnotetext{
${ }^{39}$ José Victorino Lastarria. Obras completas, Vol. V. Proyectos de Ley y discursos parlamentarios. Santiago, Tercera Serie, Imprenta Barcelona, 1907, pp. 391-426.

${ }^{40}$ Claudio Gay. Usos y costumbres de los araucanos, traducción y edición de Diego Milos, Taurus, 2018.
} 
suficientemente audaces como para demostrar que no habían perdido la valentía araucana que, gracias a Ercilla, causó la admiración del mundo entero" (Gay 76). Establece comparaciones señalando, por ejemplo que los araucanos son mucho "más orgullosos de su libertad que los chilenos" (Gay 181). Leído por el naturalista como una crónica rimada el poema de Ercilla fue en síntesis una fuente y una referencia constante para su texto sobre los usos y costumbres de los araucanos.

El químico y naturalista polaco Ignacio Domeyko llegó a Chile en 1838, exiliado de su país natal, para dar clases de química y mineralogía en el Colegio de Coquimbo, permaneciendo en el país hasta su muerte en 1889, nacionalizado chileno realizó una productiva y extensa actividad como científico, docente e investigador, fue también rector de la Universidad de Chile. A partir de un viaje a la región de la Araucanía realizado en 1845 escribió Araucanía y sus habitantes, publicado por primera vez ese mismo año. Como señala Lilianet Brintrup el texto de Domeyko presenta dos encuentros significativos: uno con la naturaleza de la región y otro con la alteridad cultural, con el habitante de la Araucanía al que el autor concibe como parte de esa naturaleza ${ }^{41}$. En ambos encuentros Domeyko -en un registro descriptivo- cita y dialoga profusamente con la obra de Ercilla. Destaca en su texto que en 1845 adquirió un ejemplar de La Araucana en Valparaíso, antes de emprender el viaje (resulta significativo que el poema estuviese en venta en el incipiente comercio librero de la época). De hecho Domeyko hace el viaje con la obra de Ercilla en la mano y su descripción de la naturaleza tiene como una de sus fuentes la descripción de la naturaleza presente en el poema, además de sus recuerdos del paisaje en su espacio natal lituano-polaco, todo ello cotejado con lo que va observando en su excursión por la Araucanía (Brintrup 29) ${ }^{42}$. Domeyko lee por una parte a La Araucana como fuente histórica que lo lleva a reafirmar ciertos valores de los habitantes que provienen del poema (libertad, independencia, amor por la tierra), su expectativa es encontrar en los habitantes de Arauco el espíritu de severidad y valentía "de sus antepasados, los Lautaros, los Tucapeles, los Colocolos, cuyas hazañas canta Ercilla (Brintrup 58). Por otra parte, lee también a La Araucana como un relato de viajes. Descripciones que hace Domeyko de espacios impenetrables y enmarañados son casi idénticas a las que hace Ercilla cuando relata los días

\footnotetext{
${ }^{41}$ Lilianet Brintrup. "Encuentros en el viaje a la Araucanía de Ignacio Domeyko: la naturaleza y el araucano". Anales de Literatura Chilena, año 4, 2003, pp. 35-57.

${ }^{42}$ Lilian Brintrup, op.cit.
} 
en que García Hurtado y su grupo estuvieron perdidos en la expedición a Chiloé, en medio de una vegetación densa y compacta.

En otro momento cuando Domeyko llega a la cumbre de Mariguenu, escribe:

...saqué del bolsillo La Araucana de Ercilla, leí como canta el triunfo de los indígenas independientes. Primero que nada me extrañaba la precisión con que pintó la forma de esta cuesta el poeta invasor: luego cita al poema: "la subida no es mala del camino/ más todo lo demás despeñadero/ tiene al poniente el bravo mar vecino/que bate al pie de un gran despeñadero, / y en la cumbre y más alto de la cuesta/se allana cuanto un tiro de ballesta (Cit. en Brintrup 49) ${ }^{43}$.

Su visión general de los araucanos con los que se encuentra y dialoga es positiva, los califica de hospitalarios y bien dispuestos a ser civilizados, en esta perspectiva le otorga un rol fundamental al comercio y a la industria, pero también a las misiones católicas.

Otro viajero de mediados del siglo XIX es Edmund Reuel Smith, miembro de una Expedición Astronómica Naval de los Estados Unidos que tenía por objeto establecer un Observatorio en el Cerro Santa Lucía de Santiago. Reuel Smith estuvo en Chile entre 1849 y 1853, y aprovechó para hacer por su cuenta un viaje a la Araucanía. El relato de su expedición fue publicado en 1855 bajo el título The Araucanians or notes of a tour among the Indian Tribes of Southern Chile, libro traducido y editado en Chile con el título de Los Araucanos $^{44}$. Se propone estudiar sus costumbres dándole al relato el formato de un diario de viaje. En general el libro es descriptivo y anuncia un propósito científico lo que se traduce en un narrador que se pretende imparcial. A veces, sin embargo, al referir las costumbres indígenas hace comentarios que evidencian una superioridad moral respecto a la religión y a la medicina que practican los araucanos (Reuil Smith 114-115), pero también el autor está consciente de sus prejuicios occidentales, y aquí y allá los cuestiona (117, 123, 203). Las referencias a Ercilla son varias y distintas. A veces recurre a su obra para agilizar algún relato (233), otra para hacer patente las carencias de Ercilla en lo que a descripción realista de los araucanos se refiere $(124,195)$. Respecto a las figuras míticas e idealizadas por La Araucana señala que quedó desilusionado debido a que no “corresponden a mi concepto de la gente indomable descrita por Ercilla" (167). También

\footnotetext{
${ }^{43}$ La cita del libro de Domeyko está en Brintrup 49.

${ }^{44}$ Edmonf Reuel Smith. Los araucanos. Cagtén Ediciones, 2016, edición por la cual citamos.
} 
critica cierto sesgo cultural eurocéntrico en el poeta cuando habla de las creencias religiosas, critica que Ercilla diga que es gente sin dios ni ley, probablemente el poeta "habría dicho lo mismo, o peor aún, de cualquier pueblo cuyas ideas no estuvieran conformes con las que él profesaba" (194). También, como Domeyko, se refiere a la belleza de la naturaleza y a la hospitalidad de los lonkos y de los nativos con que se encontró. Lo importante, una vez más, es el rol que cumple el texto de Ercilla como una referencia y un punto de comparación, lo que implica que el viajero no lee La Araucana como un poema sino como una crónica rimada que es al mismo tiempo una obra de valor etnográfico e histórico.

En la década del 40 se produce en Chile la que podemos considerar como la primera reescritura literaria en base a La Araucana, se trata del poema "La muerte de Lautaro" de Guillermo Blest Gana, publicado en $1848^{45}$. El poema se introduce con una descripción del atardecer, ocaso del día que anuncia el ocaso de la vida del héroe. Lautaro es presentado con los rasgos que describe Ercilla: "A él nada le intimida, que es en vano/ tratar de intimidar a un Araucano/", "Las ideas queridas/ de patria y Libertad, por quien mil vidas/ gustosísimo diera" (79). Se incluye también una arenga como las que pronuncian los héroes en el poema, con el objeto de motivar el brío y la valentía de los guerreros. A diferencia de las reescrituras que se hicieron en España sobre personajes como Caupolicán y Colocolo, que los inscribían en un código contrarreformista ${ }^{46}$, en el caso del extenso poema de Blest Gana hay no un cambio de registro sino una expansión y recreación de los valores y la descripción que se hace de Lautaro en la obra de Ercilla.

\section{A modo de conclusión}

En los precursores de la Independencia Hispanoamericana (Francisco de Miranda y Simón Bolívar) ya opera la invención de una tradición que considera la resistencia araucana como un antecedente que augura la emancipación de Chile y la construcción de una república. Invención de una tradición que tuvo su fuente en La Araucana y en la glorificación idealizada de la resistencia de Arauco, a pesar de que el mundo araucano-

\footnotetext{
${ }^{45}$ Guillermo Blest Gana. "La muerte de Lautaro". Revista de Santiago, Tomo I, 1848.

46 Ver al respecto en "Recepción de La Araucana en España y Europa: nacionalismo literario, canon migración". Revista Universum, segundo semestre, 2020.
} 
mapuche fue -como señalan varios estudios- más bien ajeno a la contienda de la Independencia e incluso alineado en algunos momentos con el bando realista. Lo que se inventa es el vínculo entre el pasado ancestral y la lucha por la independencia, la imagen de una posta, y no el carácter indómito y la larga lucha por su soberanía que sitúa a los araucanos como un caso único entre los pueblos originarios del continente. Se perfila así un imaginario que desde un discurso dominante perfila un Otro en perspectiva de asimilación, en la paradoja de una valoración simbólica y de una desvaloración que los invisibiliza como sujetos reales con una cultura diferente. Fueron figuras de los primeros gobiernos post independencia como José Miguel Carrera, Bernardo O’Higgins, Ramón Freire y Francisco Antonio Pinto e intelectuales como Camilo Henríquez y Juan Egaña quienes articularon y movilizaron ese imaginario desde un ideario ilustrado y republicano de cuño europeo. Se genera así un entorno histórico, político y cultural de larga proyección en el tiempo, que opera con sus contradicciones hasta el día de hoy. Contradicciones porque desde la independencia la celebración simbólica tiene su contraparte en una subyugación y exclusión en el plano de la realidad, en términos culturales, políticos y económicos. Marginación que en el siglo XIX se consolida con la mal llamada "pacificación” y la colonización interna, fundamentalmente de alemanes, suizos y franceses. Este contexto no fue urdido por Ercilla y su obra, sino que se sustenta en la recepción y apropiación de la obra, en una lectura como documento histórico del poema por la elite criolla que funcionalizó La Araucana como como fuente de patriotismo y emancipación. Es desde esa lectura que se genera una onomástica araucana, nombres que implican un homenaje que busca inscribir simbólicamente la resistencia ancestral de ese pueblo con la lucha por la independencia. Se genera así un doble discurso, por una parte se ensalza el pasado y la resistencia araucano-mapuche y por otra -desde un imaginario ilustrado y republicano- se los percibe como incivilizados y se pretende civilizarlos, sin atender a su cultura y a sus demandas históricas. Doble discurso y paradoja que en términos de exclusión y usurpación se consolida con la pacificación de la Araucanía en la segunda mitaddel siglo XIX.

Respecto a la recepción de la obra de Ercilla se perciben algunas diferencias de tono e ideario entre la generación de la Independencia y la de 1842, en que con la excepción del primer Lastarria y de Bilbao, gana presencia la dicotomía civilización y barbarie. Todos coinciden sin embargo en la necesidad de "civilizarlos". Paralelamente La Araucana a lo 
largo del siglo XIX sigue siendo un referente y un parámetro de comparación para viajeros y naturalistas. Se trata de un texto a partir del cual se genera un entorno político, histórico y cultural que a su vez va a incidir en un continuum de recepción e interpretación, estableciéndose así una circularidad en que el texto precede al contexto y a su vez el contexto alimenta nuevas lecturas e interpretaciones que se prolongan hasta el día de hoy.

Cabe por último señalar que el doble discurso que hemos advertido entre glorificación idealizada simbólica y la realidad araucano-mapuche en el siglo XIX, es una manifestación más de un rasgo que caracteriza al pensamiento ilustrado y al liberalismo del siglo: la disociación entre ideas y existencia social, tema que hemos abordado latamente en otras ocasiones. $^{47}$

\section{REFERENCIAS}

Akel, Regina. María Graham. Una biografía literaria. Universitaria, 2012.

Alberdi, Juan Bautista. Bases y puntos de partida para la organización política de la República Argentina. Valparaíso, Imprenta El Mercurio, 1852.

Albizú Labbe, Francisco. "La polémica Andrés Bello/Sarmiento. Su influencia en la formación de la identidad nacional chilena". América: Cahiers de Crical, núm. 21, 1998, pp. 211-218.

Bello, Andrés. Manual de Derecho de Gentes. Santiago, 1832.

Bilbao, Francisco. "Los Araucanos". Biblioteca Virtual Cervantes, 1847.

---. Lamennais como representante del dualismo de la civilización moderna. París, 1856.

Blest Gana, Guillermo. "La muerte de Lautaro". Revista de Santiago, tomo I, 1848.

Brintrup, Lilianet. "Encuentros en el viaje a la araucanía de Ignacio Domeyko: la naturaleza y el araucano". Anales de Literatura Chilena, núm. 4, 2003, pp. 35-57.

Cartés, Armando. "Arauco, matriz retórica de Chile: símbolos, etnia y nación". Si Somos Americanos. Revista de Estudios Transfronterizos, núm. 13, 2013, pp. 191-214.

Casanova, Holdenis. "Entre la ideología y la realidad. La inclusión de los mapuche en la nación chilena (1810-1830)". Revista de historia indígena, núm. 4, 2000, pp. 9-48.

Cavieres, Eduardo. "Desplazando el escenario. Los Araucanos en el proceso de Independencia de Chile". Studia Historica. Historia Contemporánea, núm. 27, 2009, pp. 75-98.

Cayuqueo, Pedro. Historia secreta mapuche. Catalonia, 2017.

Cid, Gabriel. Historia intelectual de la Independencia de Chile. Editorial UDP, 2019.

Coffin, J. E. Diario de un joven norteamericano. Editorial Francisco de Aguirre, 1968.

Ferrer, José Antonio (2018). "Las logias Lautaro, los Caballeros Racionales y el movimiento independentista americano". Biblioteca Juridica Virtual del Instituto de

\footnotetext{
${ }^{47}$ Véase Bernardo Subercaseaux. Historia de las ideas y la cultura en Chile, Tomo I, Editorial Universitaria, 2011 y, con Paula Cuadra, "Camilo Henríquez: teatro, republicanismo y modernidad". Alpha, Revista de Artes, Letras y Filosofía, 43, 2016, pp. 127-141.
} 
Investigaciónes Jurídicas la UNAM, https://archivos.juridicas.unam.mx/www/bjv/libros/11/5147/4.pdf

García San Martín, Álvaro. "Bilbao y Lamennais. Una lección de geopolítica". La Cañada, núm. 2, 2011, pp. 17-47.

Gay, Claudio. Usos y costumbres de los araucanos, traducción y edición de Diego Milos. Taurus, 2018.

Góngora, Mario. Estudios de historia de las ideas y de la historia social. Ediciones Universitarias de Valparaíso, 1980.

Henríquez, Camilo. La Aurora. Periódico Ministerial y Político, núm. 1, mes de 1812a.

---. La Aurora. Periódico Ministerial y Político, núm. 12, 30 de abril de 1812b, pp. 49-52.

Lastarria, José Victorino. Investigaciones sobre la influencia social de la conquista y del sistema coonial de los españoles en Chile. Santiago, Imprenta del Siglo, 1844.

---. "Proyectos de ley y discursos parlamentarios". Obras completas, vol. V. Santiago, Imprenta Barcelona, 1907.

---. Recuerdos literarios. Editorial Zigzag, 1968.

Lonko Kilapán. O'Higgins es araucano. Editorial Universitaria, 1978.

Martínez Hoyo, Francisco. "Francisco de Miranda, mentor de O'Higgins". Crítica.cl Revista Latinoamericana de Ensayo, 2014, https://critica.cl/historia/francisco-demiranda-mentor-de-o\%e2\%80\%99higgins

Méndez, Luz María. Cultura y sociedad en Chile. Nuevas miradas a los siglos XVI, XVII y XVIII. Universitaria, 2019.

O'Higgins, Bernardo. "A nuestros hermanos los habitantes de la frontera del Sud". Memoria Chilena, s.f.

Pavés, Jorge. Cartas Mapuche, Siglo XIX. Santiago, Ocho Libros/Colibrís Fondo de Publicaciones Americanistas, 2008.

Pinto, Julio y Verónica Valdivia. ¿Chilenos todos? La construcción social de la nación 1810-1840. LOM, 2017

Reuel Smith, Edmund. Los araucanos. Cagtén Ediciones, 2016.

Sanhueza, Marcelo. La américa no quiere ser imperializada. 2020. Universidad de Chile, tesis doctoral.

Vicuña Mackenna, Benjamín. "Primer discurso sobre la Pacificación de Arauco". Obras completas, vol. XII. Universidad de Chile, 1939.

Zapata, Claudia. "Juan Egaña: Cartas Pehuenches (1819)”. Historia Crítica de la literatura chilena, tomo II. LOM, 2018.

Zavala, José Manuel y Tom. D. Dillehay. "El estado de Arauco: frente a la Conquista Española: estructuración sociopolítica y ritual de los araucano-mapuches en los valles Nahuelbutanos durante los siglos XVI y XVII”. Chungará, vol. 42, núm. 2, 2010, pp. 433-450. 